\title{
Scoping a Public Health Impact Assessment of Aquaculture with Particular Reference to Tilapia in the UK
}

\author{
Andrew Watterson, ${ }^{1}$ David Little, ${ }^{2}$ James A. Young, ${ }^{3}$ Francis Murray, ${ }^{2}$ Larry Doi, ${ }^{1}$ \\ Kathleen A. Boyd, ${ }^{4}$ and Ekram Azim ${ }^{5}$ \\ ${ }^{1}$ Occupational and Environmental Health Research Group, Centre for Public Health and Population Health Research, \\ University of Stirling, Scotland, Stirling FK9 4LA, UK \\ ${ }^{2}$ Institute of Aquaculture, University of Stirling, Scotland, Stirling FK9 4LA, UK \\ ${ }^{3}$ Stirling Management School, University of Stirling, Scotland, Stirling FK9 4LA, UK \\ ${ }^{4}$ Institute of Health and Wellbeing, University of Glasgow, Scotland, Glasgow G12 9LX, UK \\ ${ }^{5}$ Department of Physical and Environmental Sciences, University of Toronto, ON, Canada M1C 1A4
}

Correspondence should be addressed to Andrew Watterson, aew1@stir.ac.uk

Received 19 October 2011; Accepted 30 November 2011

Academic Editor: C. Banwell

Copyright (C) 2012 Andrew Watterson et al. This is an open access article distributed under the Creative Commons Attribution License, which permits unrestricted use, distribution, and reproduction in any medium, provided the original work is properly cited.

Background. The paper explores shaping public health impact assessment tools for tilapia, a novel emergent aquaculture sector in the UK. This Research Council's UK Rural Economy and Land Use project embraces technical, public health, and marketing perspectives scoping tools to assess possible impacts of the activity. Globally, aquaculture produced over 65 million tonnes of food in 2008 and will grow significantly requiring apposite global public health impact assessment tools. Methods. Quantitative and qualitative methods incorporated data from a tridisciplinary literature. Holistic tools scoped tilapia farming impact assessments. Laboratory-based tilapia production generated data on impacts in UK and Thailand along with 11 UK focus groups involving 90 consumers, 30 interviews and site visits, 9 visits to UK tilapia growers and 2 in The Netherlands. Results. The feasibility, challenges, strengths, and weaknesses of creating a tilapia Public Health Impact Assessment are analysed. Occupational and environmental health benefits and risks attached to tilapia production were identified. Conclusions. Scoping public health impacts of tilapia production is possible at different levels and forms for producers, retailers, consumers, civil society and governmental bodies that may contribute to complex and interrelated public health assessments of aquaculture projects. Our assessment framework constitutes an innovatory perspective in the field.

\section{Background}

The study aimed to explore the public health impact assessment (PHIA) of tilapia aquaculture using a range of health impact assessment (HIA) techniques. This was with particular reference to the UK and geared to informing such assessments, primarily at a sectoral level, for those producing, distributing, selling, and consuming such fish in the future and those responsible for monitoring public health with regard to tilapia production or facilitating economic development in rural and urban areas through tilapia production. To do this we produced simple tools such as matrices, charts, and checklists that assist in carrying out assessments. Impacts in this context cover environmental health, occupational health, and related economic and social aspects that play into the wider public health assessment.

The Rural Economy and Land Use- (RELU-) funded, 3year, research project upon which this paper is based was designed to explore, through multidisciplinary approaches, technical, marketing, and public health aspects of sustainable tilapia aquaculture in the UK [1-4]. Tilapias are fresh warm water herbivorous and detritivorous white fish from the tropics that can be farmed in temperate regions, provided that warmwater (25 degrees C) minimum conditions can be maintained. This raises the possibility that they can be produced as either a stand-alone enterprise or integrated 


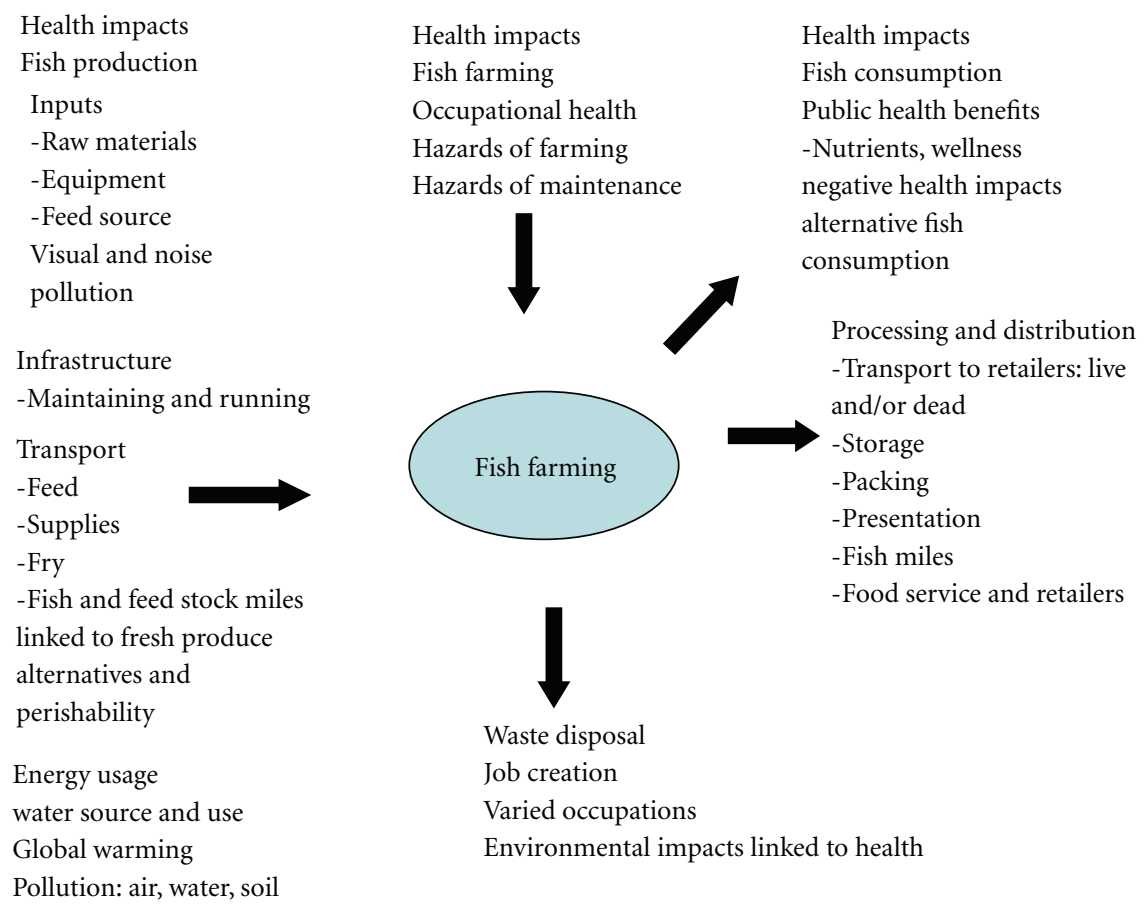

FIGURE 1: Some types of environmental and health impacts that fish farming in general could have for UK tilapia production.

with other rural or possibly urban activities. Data were generated from all three disciplinary perspectives and fed into an integrated analysis of the project. The focus for the project was not primarily on juvenile production but rather on the technical and commercial viability of food fish farming in closed systems operated by agricultural farmers across the UK who were seeking to diversify from terrestrialbased food production. Relatively little data exist about postharvest impacts of tilapia farming in the UK. However, information was also gathered on certain aspects of tilapia production in Asia which produced comparative data for this paper.

The public health component of the research project investigated the development of tools across the fish farming industry generally, for what has been termed a public health impact assessment (PHIA) [2]. The hazards of fish farming have been relatively neglected $[5,6]$. Current aquaculture practices can create both environmental pollution problems and risks for workers, local communities, and consumers. With global aquaculture fish production rising at an average of over $8 \%$ a year between 1970 and 2008, with 65.8 million tonnes of such food produced in 2008, and with projections that aquaculture globally by 2030 could produce between 79 and 110 million tonnes, the implications for public health are considerable $[7,8]$. Hence more research is needed on these potential effects and how to intervene appropriately to prevent or reduce them [9]. Our research entailed some assessment of the impacts of the various stages of fish production specifically in the UK and also informed by research in Thailand and an exploration of the perspectives of consumer, farmers, retailers, and the wider public. We explored why it might be possible to base production on feed that was intrinsically less resource intensive than competitive species in such an environment. The concept was to be able to grow tilapia on natural food (biofloc) grown within the culture system in a similar way to how the fish can be grown in the tropics. Specifically we sought to determine the potential of a culture system, Activated Suspension Technology (AST) that in principle required the use of lower-quality feeds that could be sourced locally and simpler management compared with the conventional Recirculation Aquaculture Systems (RASs) used for warmwater aquaculture in temperate climes.

In the UK because of recency, scale, and type of tilapia farming, unlike larger tilapia farming sectors elsewhere in the world, many impacts on the environment and public health will be minimal. Nonetheless it is important at this emergent phase to also consider possible socioeconomic impacts in terms of conflicts over resources and working conditions of production employees.

Hazard and risk perception, assessment, and potential management processes can prove that problematic and cost and risk benefit assessments are difficult because data are often limited, incomplete, or unavailable. The occupational and environmental hazard assessment of tilapia farming is less subjective than wider environmental and socioeconomic risk assessments. Figure 1 illustrates some of the types of environmental and health impacts that fish farming in general could have; these impacts are considered specifically for UK tilapia production.

This paper offers a first tentative scoping of the potential public health impact of tilapia farming in a number of settings. It reveals both possibilities and challenges for producers and the communities in which they function, retailers and consumers. 


\section{Methods}

The health effects of particular industries and their related activities are often many and varied for workers in the industry, for consumers, and for communities. They can be highly complex and are often interrelated and interdependent. There may be a classical absence of evidence to make the assessments rather than evidence of absence of risks. The multimethods used in the study included literature searches of aquaculture and its impacts generally and papers specifically relating to tilapia.

This provided a contextual framework within which we assess data collected by the RELU project in the UK and Thailand. Data sources included field trials in Asia (2006-2007) and lab trials in Stirling University's Institute of Aquaculture (2005-2007). Technical trials were carried out in two separate facilities: the Tropical Aquarium of the Institute of Aquaculture (IOA) and a commercial operation in Thailand. A series of three consecutive trials was set up at IOA to assess the fundamental aspects of AST under light limited conditions. The controlled small-scale facility in which an AST system of replicate tanks was set up proximal to an RAS facility allowing monitoring of nutritional quality of biofloc (bacteria and other microorganisms attached to nonliving particles), its constituent species makeup, and the growth and welfare of stocked fish. The third trial assessed the performance of a hybrid RAS system with a periphyton module for improving water quality and nutrient recovery within the system. A series of four consecutive trials was designed and implemented at Nam Sai farm, Thailand, to allow comparison of AST and RAS systems on-farm and offfarm cage and pond culture enterprises.

There were 9 visits to tilapia farmers in the UK and 2 visits to facilities in The Netherlands, where observational and empirical data were collected, feedback from a stakeholder group of producers, civil society bodies, and researchers familiar with tilapia production and related issues relating to the RELU project objectives.

Additionally, consumer and market research was conducted. A total of 11 UK focus groups were undertaken in Edinburgh, Glasgow, Stirling, Bradford, and London (November 2005-June 2006) to explore consumer attitudes toward health, environmental, and sustainability issues with food and fish. A week long tilapia product placement exercise in two food service outlets in Devon (September 2006) was also undertaken, comprising of 30 face to face short interviews with consumers regarding their opinion of and reasons for choosing tilapia from the menu and a further two interviews with the restaurant owners. Numerous supply side semistructured interviews were also undertaken with fishmongers $(\times 6)$, ethnic grocers $(\times 2)$, and food market stall holders $(\times 3)$ in London (June 2006), and with fish processing and supply companies $(\times 2)$, restaurants $(\times 5)$, fish markets $(\times 1)$, and fishmongers $(\times 2)$ in Devon (October 2006). These gauged their perceptions, knowledge of and attitude towards tilapia, and any further retail, processing, or distribution information, such as price and preferences for types of tilapia products: fish weight, fish form (fillet or whole), and state (fresh, frozen, or other added value). The
RCUK RELU data set provides further details of the wide range of research undertaken for the tilapia project.

Effective risk management of environmental health hazards should include participation of all those stakeholders involved [10]. Whilst we have not used frameworks like those based on the US National Research Council work, we have been informed by producers, retailers, and consumers and, in turn, helped to inform them about issues raised by tilapia farming, all of which have helped in the development of the PHIA.

As this is a "scoping" stage of a PHIA and the development of apposite tools, it combines elements of EIAs, EHIAs, and Occupational Health Impact Assessments (OHIAs) [2]. It follows some but not all of the minimum guidance elements for a HIA [11] and is aimed at informing decisions for a variety of governmental, economic, and civil society bodies. It considers specifically, albeit not comprehensively, potential impacts on some health outcomes as well as on social, environmental, and economic health determinants. It has solicited and utilized input from stakeholders. HIAs are usually applied to specific projects or developments but the small size of the tilapia industry in the UK provides an opportunity for such tools to be applied nationally and scoped across a range of sectors.

Establishing baseline conditions for health outcomes, in terms of tilapia consumption alone, was not possible because of the many and varied diets that consumers have. Moreover data capture of trade in tilapia, let alone consumption, is recent and imperfect. However, some of the possible health outcomes for producers and their communities and for consumers and subpopulations have been considered. The trees, tools, and matrices produced may provide a basis for recommendations to protect and promote health and environmental sustainability.

Approaches used include Life Cycle Analyses (LCAs), matrices, cost and risk benefit analyses, and models of analytic-deliberative-risk-management frameworks running through to impact analyses $[2,10]$.

\section{Results}

3.1. Environmental Impacts. Two forms of assessment were considered, EIAs and LCAs. EIAs have been widely used for several decades, although only to a limited extent in aquaculture but questions remain about food security, environmental sustainability, pollution, biodiversity, rural and remote effects and the related evidence bases for assessment and policy formulation with regard to aquaculture. Aquaculture can be viewed both as a major source of good nutrition for an ever growing world population and/or as a threat in some settings to subsistence fishing and water supply in vulnerable communities. It can be an effective means of food production or a cause of pollution, an addition to varied diet, and a mechanism to reduce uncertainty in the availability of traditional wild captured fish supplies or a cause of decline of wild fish species. Much depends on the location, scale and intensity of the enterprise, the type of fish farmed, farming practices and management, and regulatory controls and enforcement. Health, environmental, 
and economic impact assessments of tilapia production may therefore vary depending on where, how, and when it is produced.

The Canadian International Development Agency (CIDA) developed a sectoral environmental assessment tool "to identify the major potential adverse environmental health effects, associated mitigation measures, and guidelines, as well as environmental indicators for fish farming and aquaculture initiatives" [12]. Human concerns included land use, tenure, and management practices; water supply conflicts; seed, meal, antibiotics, drugs, hormones, parasiticides, and other pesticides; health and safety; and antifouling agents. Siting of such activities and their impacts-negative as well as positive-on "ways of life" and culture characteristics also merited listing as a concern as did species selection and production systems linked to water quality and quantity, climate, and likelihood of natural disasters. This Canadian tool contains not only assessments of major potential adverse effects but also measures to mitigate or remove such threats.

LCAs provide the best evidence about the impacts of many food, fishing, and related industries but can be expensive and time-consuming in the short term and can provide relatively little information directly about health [13-15]. No comprehensive LCAs of tilapia currently exist although one explores frozen tilapia in Indonesia [16]. One valuable comparative caged tilapia/carp LCA has been conducted for the purposes of environmental management in a reservoir setting in Indonesia [17]. The study examined resource use, pollutant emissions, and waste generation of fingerling production, fish rearing, and transport of fish. The research, using field observations and modelling, found that reducing the food conversion ratio reduced the potential impacts on climate, acidification, and water dependency by between 41 and $60 \%$.

These findings do not easily translate to UK tilapia production although there will be several common factors. However, human health is only marginally addressed directly in such approaches [18]. Figure 2 illustrates their LCA approach.

WWF recently reviewed the impact of tilapia in economically expanding countries. It noted that "the increased demand for tilapia has shifted many tilapia producers from subsistence growers to larger, export-driven producers. This shift has created environmental impacts-both real and perceived" [19]. The WWF analysis has, however, been contested as possibly driving production in the wrong direction especially when generally domestic urban production and consumption with tilapia can be more important in several regions of the world. Some call for a more holistic approach to tilapia certification [20]. These impacts included water effluents and consequent effects on aquatic plants and animals threats to ecological integrity in terms of over-stocking and related virus and disease spread or habitat consequences, pollution linked to excessive use of feeds and fertilizers, and farming of an invasive species. However it might also be noted that benefits may also result from provision of local employment and income multiplier effects, export earnings opportunities, and scope to import alternative lower-cost food substitutes. These and other benefits are considered

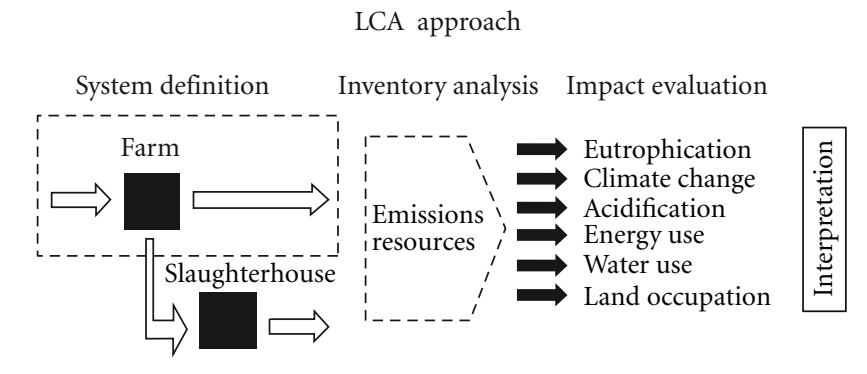

Expressed per functional unit (e.g., kg of meat)

LCA of tropical production systems: case studies

Figure 2: LCA Approach.

later in the paper as well as why a warmwater fish might be "sustainable" in a temperate environment.

Specific environmental impacts occur in any aquaculture system including tilapia production although temperate and tropical production systems will often vary significantly. Tilapia may require water, tanks, various types of machinery, heating, feed, veterinary products, and equipment although not necessarily new buildings. They will incur transport costs and related energy and air pollution-of fry and fingerlings, feed, and equipment. They require energy for storage, distribution, and retail of the products and disposal of wastes from fish prepared for market. High fish miles and the quest to sell live fish to distant market segments could affect environmental impacts, quality, and food safety. Farm shops and the supply of local markets might reduce fish miles. Where such fish farming occurs in large conurbations with much demand for tilapia from a larger population, "fish miles" could be significantly reduced.

Heating, insulation, and aeration factors influence the environment. Heating and air exchange to reduce carbon dioxide levels in work units are two substantial costs to tilapia growers and may create significant environmental impacts within a unit but minimal impacts beyond considering the small scale of UK units.

The use of certain fish feeds may be problematic in terms of sustainability and impacts and recent reviews have noted the unsustainability of marine product use in aquaculture and the human health imperative [21, 22]. Fish meal and fish oils may be added to tilapia diet. This could enhance its consumption value by providing humans with omega3 fatty acids but the evaluation of their environmental effects remains limited or open to interpretation. There have been recent challenges to the argument that fishmeal or oil is unsustainable compared to use of terrestrial feed ingredients [23]. Our research showed that AST was not more biologically efficient than RAS and certainly not more economically attractive but pond-based production in the tropics can be very productive without any use of fishmeal/oil and this is how most tilapias are still produced.

Biosecurity issues may also be present and could produce potentially adverse impacts. In the UK, one of the farmers interviewed for the research project was interested in buying directly from overseas, hence supporting livelihoods in 
developing countries. This is a much more cost-effective source of seed given the relatively small numbers required by UK producers. The project did support a UK-based juvenile producer that appears still dependent on sourcing overseas.

Again indirect public impacts of potential infections relate to energy and material and transport costs of replacing fish batches and also implications for air, water, and soil pollution. Another farmer purchased a batch of fish that was found to contain an ectoparasite which caused high initial fish mortalities. These impacts sometimes do not present any threat to the workforce but indirectly may threaten the viability of the tilapia producer and hence could impact upon job security and so public health. Poor management of pathogens could also lead to cross-infections. Direct human health risks have emerged with regard to fish borne zoonotic trematodes on which comparative data exist for tilapia and other species [24].

With tilapia, certain production systems could eliminate fish and meat meals in feeds [3]. The AST production system could also use locally produced ingredients around farms although, in urban areas, this would not usually be possible. Some small-scale farmers growers used trout pellets but indicated that they would purchase turkey pellets in future because of expense and improved nutrients. In general highly digestible diets work best in RAS systems where performance is closely related to maintaining optimal water quality. Water stable balanced formulations are likely to be most cost effective and environmentally benign (i.e., with least effluent nutrients). Pooled resources for small growers with better information about feeds could well lead to reduced environmental and health impacts. However, the market for tilapia is undeveloped in the UK and prices of feed used do not reflect production costs.

Tilapia will not survive in UK open waters and therefore should present no threat to indigenous species through either competition or disease. This is atypical for aquaculture in general where arguably the introduction of exotics and/or associated pathogens/parasites has had major impacts. A recent review of tilapia introduction into Asia, however, found very little evidence of negative impacts and significant benefits [25]. Tilapia environmental and health impacts in this respect are therefore unlike those of salmon and trout.

Waste removal applies to all fish farms but UK tilapia production thus far has been on a comparatively small scale and, hence, in volume terms, less problematic.

Additionally waste removal was not expected to be a major challenge especially as RAS systems produce a concentrated nutrient-rich sludge that has value for horticulture [4]. One tilapia farmer in the study had difficulties with solid waste.

3.2. Health Impacts. Data about human illness and wellbeing impacts are far harder to collect than those on environmental pollution due to problems of diagnosis, recording, reporting, and documenting. This is especially the case with chronic or subacute diseases. Small employers and the selfemployed in the UK often do not report health problems and government agencies acknowledge such under-reporting [26]. A small number of studies have recently focussed on more systematic assessments of particular health fields such as the occupational health and safety in aquaculture to lay the foundations for prevention of disease and injury [27, 28]. Integrating HIAs with wider assessments has been mooted as a means of avoiding multiplication and/or duplication of such assessments [29]. HIAs have been defined by the WHO as "a combination of procedures, methods and tools by which a project, programme, policy or legislative proposal may be judged for its potential effect on the health of a population and the distribution of these effects within it" [30].

3.2.1. Human Consumption of Tilapia. There is much debate about the nutritional value and hence dietary impacts of tilapia [31] linked to feeds used. Tilapia provide lean protein and in the UK consumption is currently negligible, but even given its expected potential, any contribution to diverse diets might be expected to remain limited. In cultures where fish consumption is much higher, and tilapias are significantly substituting for wild stocks, their direct nutritional value is likely to be much more important. Some studies have indicated that farmed tilapia contains comparatively high levels of omega- 6 fatty acids and lacks sufficient omega-3 fatty acids $(n-3)$ [32]. Such imbalances in humans are linked to heart disease and other illnesses. In 2006 tilapia studies in Thailand indicated that wild fish had a more favourable fatty acid (FA) profile for human consumption as they contained higher ratio of $3 \mathrm{~s}$ to $6 \mathrm{~s}$ than intensively farmed fish. This led to feed recommendations to reduce $6 \mathrm{~s}$ in intensively reared tilapia through substituting vegetable oils rich in $6 \mathrm{~s}$ with oils rich in other fatty acids such as $n$-3s [33]. However, intensively reared tilapias have more $3 \mathrm{~s}$ and it is the ratio that is believed to be more important in human diets. A recent review found "wild tilapia (did) have more FAs than farmed tilapia" but that farmed fish would still form part of a balanced diet globally [34]. In the UK, tilapia feed will play an important part in assessing the health impacts of the fish on consumers linked to accurate information provided by tilapia producers worldwide and made available by retailers.

Women's consumption of fish in particular presents additional reproductive risks and benefits [35]. Risks relate to ingestion of contaminants such as methyl mercury, persistent organic pollutants like polychlorinated biphenyls, dioxins, and organochlorine pesticides. Benefits relate to substances that may aid foetal development and contribute to mothers' and adult women's health. Relatively little research has involved tilapia in this context and risk assessments for home produced fish may vary considerably from those produced in Asia, South America, or Africa. Farmed tilapia may not be exposed to some of the industrial contaminants that appear in wild fish [36]. One recent Canadian study based on a survey of 18 fish species indicates that tilapia could be eaten twice a day in moderate quantities by pregnant women thereby enhancing beneficial intake of docosahexaenoic acid (DHA) without risks to the foetus from mercury and avoiding any need for supplements [37]. Tilapias have some of the lowest mercury levels according to FAO and US sources [38]. 
Tilapias, in common with other cultured herbivorous fish, had low levels of contaminants compared to wild fish [36]. Direct human health risks have emerged with regard to fish borne zoonotic trematodes on which comparative data exist for tilapia and other species [24].

\subsubsection{Environmental Health Impact Assessments (EHIA).} These have been floated, within an EIA framework, as a tool to address specific health concerns. EIAs have often been applied to aquaculture development projects but HIAs far less frequently and EHIAs hardly at all. The use of some form of integrated PHIA in aquaculture and indeed beyond may be of value to policy-makers if the assessments draw together not only environmental and broad-based health considerations but also environmental and occupational health and safety information that is often neglected but may be of significance to public health [39]. If duplication occurs and if generation of data makes the assessments cumbersome, costly, and time-consuming without adequately informing decision-makers, they will be of little value and limited use. However, once data are available for an activity, they may be applicable to PHIAs as is the case with assessments of organochlorine pesticides in Chinese fresh water fish ponds [40].

All UK tilapia farmers visited in the RELU project had persistent poor water quality problems and this was noted to have its roots in poor technical or construction choices, principally the reliance on drum-filters as the sole means of water clarification. Poor water quality is likely to build up diffused $\mathrm{CO}_{2}$ and $\mathrm{NO}_{X}$, promote diseases, and reduce fish quality. However, there are also public health implications in terms of treatment costs, water usage, and knock on effects of energy usage and material costs. This would not impact on public health unless there were significant effluents flows from the system which should not occur if systems worked effectively. High stocking densities and poor husbandry linked to inadequate management in some tilapia production units lead to suspended solid waste affecting water quality and present conducive conditions for certain microbial growth that could threaten public health (e.g., Streptococcus sp) and does not contribute to the production system. Although the potential public health threat from rare genotypes of Streptococcus agalactiae in tilapia in Thailand may be serious, the problem is not a major one in the UK [41].

Major aquaculture animal feed contaminants could contain "salmonellae, mycotoxins, veterinary drug residues, persistent organic pollutants, agricultural and other chemicals (solvent residues, melamine), heavy metals (mercury, lead, cadmium) and excess mineral salts (hexavalent chromium, arsenic, selenium, fluorine), and transmissible spongiform encephalopathies" [42]. There will be public health impacts from the collection, processing, transport, and use of feeds. The type of feed, the quantity, and the delivery and disposal systems may all produce different impacts for producers, consumers, fish workers, communities, and the wider public.

Assessment of chemicals used in fish veterinary treatments or in disinfectants, antibiotics, and related products is complex [43] and includes "physicochemical properties, amount used and method of administration, treatment type and dose, animal husbandry practices, manure storage and handling practices, metabolism within the animal, and degradation rates in manure and slurry. Once released to the environment, other factors such as soil type, climate, and ecotoxicity determine the environmental impact of the compound. The importance of individual routes into the environment for different types of veterinary medicines varies according to treatment and livestock category.... Treatments used in aquaculture have a high potential to reach the aquatic environment" [44]. Chemical assessments initially related to marine salmon farms rather than the closed system type of farming that would be used for tilapia [45].

The downstream impacts of fish farming chemicals could be substantial although establishing any causal links may be problematic because of study design and multiple exposure issues. In Hungary exceptionally high rates of Down's syndrome were reported in a small village, and a case control study indicated that very high levels of trichlorfon used in local fish farms and contaminating local water supplies could have been a cause. All affected mothers had consumed contaminated fish during the critical period. The chemical's use was prohibited and no further congenital abnormalities occurred [46]. Such geographically confined studies are rare but highlight the need for EHIAs to be conducted on fish farms where risks can be identified and removed prior to production commencing. These can usefully be linked to hazard analysis at critical control point (HACCP) regulations in aquaculture [47]. In the USA, in 2002, some detectable levels of antibiotics were identified in water samples at a relatively small number of both extensive and intensive state fish hatcheries sampled although no private hatcheries were tested [48]. This indicates a potential public health threat, the need for remedial measures, and inspections of private hatcheries.

Public health concerns about antimicrobial drug resistance in humans due to veterinary treatments in mammals consumed by humans remain high. In 2003, a WHO/FAO/ IEE expert working group was clear that "available scientific evidence shows that also antimicrobial usage in horticulture, aquaculture and companion animals can result in spread of resistant bacteria and resistance genes to humans" [49]. Little research has been done on this potential risk with regard to fish consumed by humans but concerns were sufficient to lead to a WHO/FAO/OIE expert consultation on the subject in 2006. This consultation found that there was more limited use of antibiotics in aquaculture than other sectors and in some countries usage was dropping. Nevertheless, large quantities of antimicrobials are used in aquaculture in some countries, often without professional consultation or supervision. UK tilapia production, which is low, uses relatively small quantities of registered chemicals unlike other countries where availability of registered antimicrobials is insufficient and contributes to illegal use [50]. Lack of good data on usage and details on pathways of gene flows was found to restrict detailed risk assessments [51, 52]. During the mid to late 2000s, the use of methyl-testosterone with tilapia raised questions about the lack of standards relating to occupational and environmental health and safety which 
were needed to protect workers' health and to ensure that methyl-testosterone did not pollute water leaving tilapia farms [53, 54].

Fish farming disinfectants, one of a group of antimicrobials which also include antibiotics, that may be used in fish farming, and their interactions have been under-researched [55]. Production benefits may be clearer than the risks. Early work on disinfectants focused primarily on benefits [56]. Yet "antibiotics, disinfectants and bacteria resistant to them have been detected in environmental compartments such as waste water, surface water, ground water, sediments and soils" [57]. Since that time, there has been greater debate about potential antibiotic threats to human health from their usage in aquaculture $[58,59]$ and some wider concerns about both public health and animal health impacts [60]. Oxytetracycline and florfenicol have both been used as antibiotics in tilapia. In the USA, in 2000, they had been found in other fish and withdrawal times were set for them of 21 days for catfish and 12 days for salmon [61].

For consumers, pollutants, contaminants, and residues may be low but with unknown consequences. For example, a recent analysis of red tilapia in Malaysia indicated relatively low levels of pesticides and antibiotics: in 3 of 180 fish sampled from farms and markets [62].

3.2.3. Occupational Health and Safety Impacts. The focus for aquaculture controls has been linked to the marketing and sale of fish products and international certification schemes have tended to reflect consumer and producer priorities sometimes with no reference at all to worker health and safety [63]. Industry-specific guidance for tilapia is wider and provides a framework for consideration of most of the topics discussed below where a range of health and safety impacts have been identified. "Walk through" visits of 5 UK tilapia farms for the RELU project identified a wide range of potential health and safety impacts on operatives. Other risks include fire and adverse welfare impacts on workers. Not unique to tilapia farming is the lack of occupational health histories and robust data on ill-health and injuries which applies to the UK workforce as a whole.

Occupational hazards from diseases affecting tilapia have been reported [61] and antibiotics may serve to protect workers and consumers by preventing or treating fishborne diseases. Alternatively they may expose workers and consumers to risk from antibiotic resistance. In the 1990s, the fish pathogen Streptococcus iniae was responsible for invasive infections in North American workers who handled shopbought farmed tilapia with problems identified both in the aquaculture ecosystem and in fish in shops [64, 65]. Vibrio vulnifcus affected hundreds of workers handling live tilapia produced by aquaculture in Israel $[66,67]$.

This has led bodies such as FAO to consider the public health and hence occupational health consequences of tilapia fish farming. Streptococcus sp. infections of fish are a relatively newly identified threat to humans and have been found in cultured tilapias; S. iniae and other Streptococci that infect fish may also infect humans. Infections have been contracted when people market live fish, or consumers are cut or spinned during handling or preparation of the fish. "The disease appears most prevalent in intensive tilapia production systems, in which water quality is marginal and/or there is environmental stress or trauma to the fish [65]. It has not yet been associated with fish from integrated culture systems" [68].

Occupational health impacts from pesticides, disinfectants, and antibiotics will depend on extensive good quality data on acute and chronic effects, the route of entry, concentrations, the level of exposure, the length of exposure, container and application design, mixing and handling equipment and facilities, the uptake in the body, general working conditions including temperature and humidity, personal protective equipment available, suitable, worn condition, combinations of substances and working conditions, and so on [69]. In the UK use of these substances may be relatively limited with regard to tilapia; exposures may be low and for relatively short periods of time. Nevertheless, in the UK incidents have been recorded of major chemical exposures among fish farm workers but not tilapia farmers [39]. The risks may also be increased because of inadequate or inaccessible information about those hazards, poor education and training, nonliteracy in the chemical label languages, poor systems of work, and deficient risk management.

Identifying chemicals used in tilapia production in the UK is itself not a simple task. Some chemicals and therapeutants require market authorisation and others do not. Market-authorised products will be licensed by the Veterinary Medicines Directorate Veterinary Licensing Authority in the UK and by the Veterinary Medicines Agency in Europe. There are no comprehensive lists of such chemicals for aquaculture available from these bodies. However, we have listed some of the major chemicals that we know have been recently used specifically in tilapia aquaculture in the UK. What also affects impact assessments is the lack of data on chronic low-level effects and mixtures, the contradictory nature of some data sheets, and in several instancesparticularly with regard to antibiotics, the serious long-term human effects of relatively small exposures.

With regard to chemicals and antibiotics in tilapia production, the assumptions built into the assessment relate to the following. "Among doctors, veterinarians, farmers, and patients, the "prescription only" use of antibiotics has to be supported in all sectors, including agriculture. Also, phasing out all uses other than direct use as therapeutic agents has to be pursued" [61]. The impact of tilapia antibiotics is therefore predicated in the UK, following Serrano's FAO guidelines on good data on use and exposures of fish, consumers, and workers to such pharmaceutical products, effective monitoring, application of good principles and practices across the sector, effective licensing controls, and the operation of good husbandry and hygiene standards and immunisation of fish. This should lead to limiting antibiotics to therapeutic and not prophylactic use. To what extent small tilapia producers will possess the necessary knowledge, training, advice resources, equipment risk assessment, and risk management expertise to control health impacts is unknown and may prove highly variable. There may be 
significant differences in risks in workplaces where there is effective governance and where there is not. The impacts of external private governance (standards setting/certification) on such risks are difficult to research independently but may be factors, good or bad, on risk control.

In the RAS tilapia production systems, a number of chemicals listed in Table 1 could be used, often at low levels and in small amounts. Some of these chemicals present acute and chronic occupational health hazards but only incidents involving high level acute exposures have been reported in UK fish farming [39]. UK health and safety management, training, information, and supervision in small and medium sized enterprises can be poor and agriculture has one of the worst health and safety records [39]. The nature of RAS or indeed AST makes use of many chemicals problematic as antimicrobials can destroy the water treatment properties of the systems. The key advantage is that such systems can ensure high levels of biosecurity compared to open systems. Where tilapia farming is a secondary activity on a farm, there may be additional risks involved in terms of unfamiliarity with chemicals and the lack of safety systems of work. Whilst livestock farmers and workers are likely to be very familiar with the disinfectants used in tilapia farming and the health and safety risks attached to them in their principal work activities, they may be unaware of the different impacts they may have on culture systems. Such famers could, however, also be exposed to a wider range of antibiotics than normal through tilapia production.

Long-term and low-level occupational effects of tilapia chemicals have not been specifically researched. The list contains a number of respiratory and skin irritants such as sodium alkyl benzene sulphonate and sodium hypochlorite and some carcinogens such as formaldehyde [70, 71]. Several antibiotics may cause microbial resistance and a few, such as florfenicol and oxytetracycline hypochloride, have been linked to adverse reproductive effects in males or females at various levels of exposure. Specific chemicals such as sodium hypochlorite are often included in EHIAs. A HIA has also been done for formaldehyde with regard to acute and shortterm effects of lowering occupational exposure limits [72]. Otherwise environmental health data may be sparse. The chemicals and antibiotics used may have a public health impact in terms of their original production on workers, their transport, their application by tilapia fish farm workers, their take-up in fish for consumers, their wider impacts possibly in terms of water pollution albeit at low levels, and their impact on antibiotic resistance.

Various other potential hazards were identified in our research. These included trips and falls. Daily or frequent washing of the drum-filter could mean that workers are prone to respiratory infections but no detailed information exists on this. Air quality issues existed on several tilapia farms due sometimes to an absence of extraction fans. Respiratory and eye irritation may potentially be associated with hand feeding fish several times a day. Heating systems can have impacts on worker health and safety although these may be generic to many farm buildings and may not be specific to tilapia producing units. Several farmers used air blowers for tank aeration producing noise levels that presented those working in the units with occupational deafness risks. Also the location of blowers within the growout units for heat loss reduction may be a significant noise polluter. Occupational and environmental noise pollution would depend on the nature of the buildings and the proximity of residential properties. The locations of blowers within the grow-out tilapia units for heat loss reduction present serious occupational noise problems in terms of both decibel levels and length of time of exposures.

Farmers face a wide range of work-related upper limb disorder (WRULD) threats and there may be little specific to tilapia farming. However, diversification into tilapia farming creates another additional set of tasks to perform. The risks may be the same as other ergonomic risks for farmers. Good design and better siting, as elsewhere on farms and in industry, should reduce the problems significantly. Handfeeding tilapia up to 5 times per day could present repetitive strain injury threats. Reducing the number of feeds whilst not compromising production would appear to be a solution. Manual killing of fish on ice baths could present additional work-related upper limb disorder risks.

A number of the farmers interviewed found tilapia farming development "stressful" in terms of learning new skills, introducing "new" technologies, and running production systems that were unfamiliar to them or labour intensive. But such stresses would be similar to any new farm developments. Stresses created by not diversifying and developing alternative income streams might be as damaging as those of innovating. Similarly, early adoption phases of new species are liable to be associated with greater anxiety over issues of market acceptance and attendant financial risks. This may be even more marked where producers are diversifying from traditional lifelong skills sets and expertise gained in terrestrial production and engaging with waterbased systems. Factoring in such elements to a HIA depends on knowledge of the regional and local economy and labour markets as well as an understanding of market opportunities for tilapia in different sized and differently configured farm units.

Farmers with relatively small units where production costs were high found that there could be additional stresses. However, this was sometimes compensated for by increased profits as well as contributed to community needs with associated well-being benefits. On some farms, only one full-time member of staff dealt with the tilapia. They were responsible for almost all the activities including security at the farm. The hazards of lone working also applied although small farms would often involve lone workers anyway, and in this respect, the safety threats of a fish farm were no greater than those of general farming. This said, the relative novelty of fish farming might be expected to induce higher stress levels for otherwise comparable situations. Staff on one farm all commented on weight loss possibly the result of greater physical activity due to additional tasks related to the tilapia production or heat in tilapia production units. Such effects could have been either beneficial or detrimental to their health and well-being. Longer hours would certainly have impacted on their family and personal lives but there may have been job security benefits. 


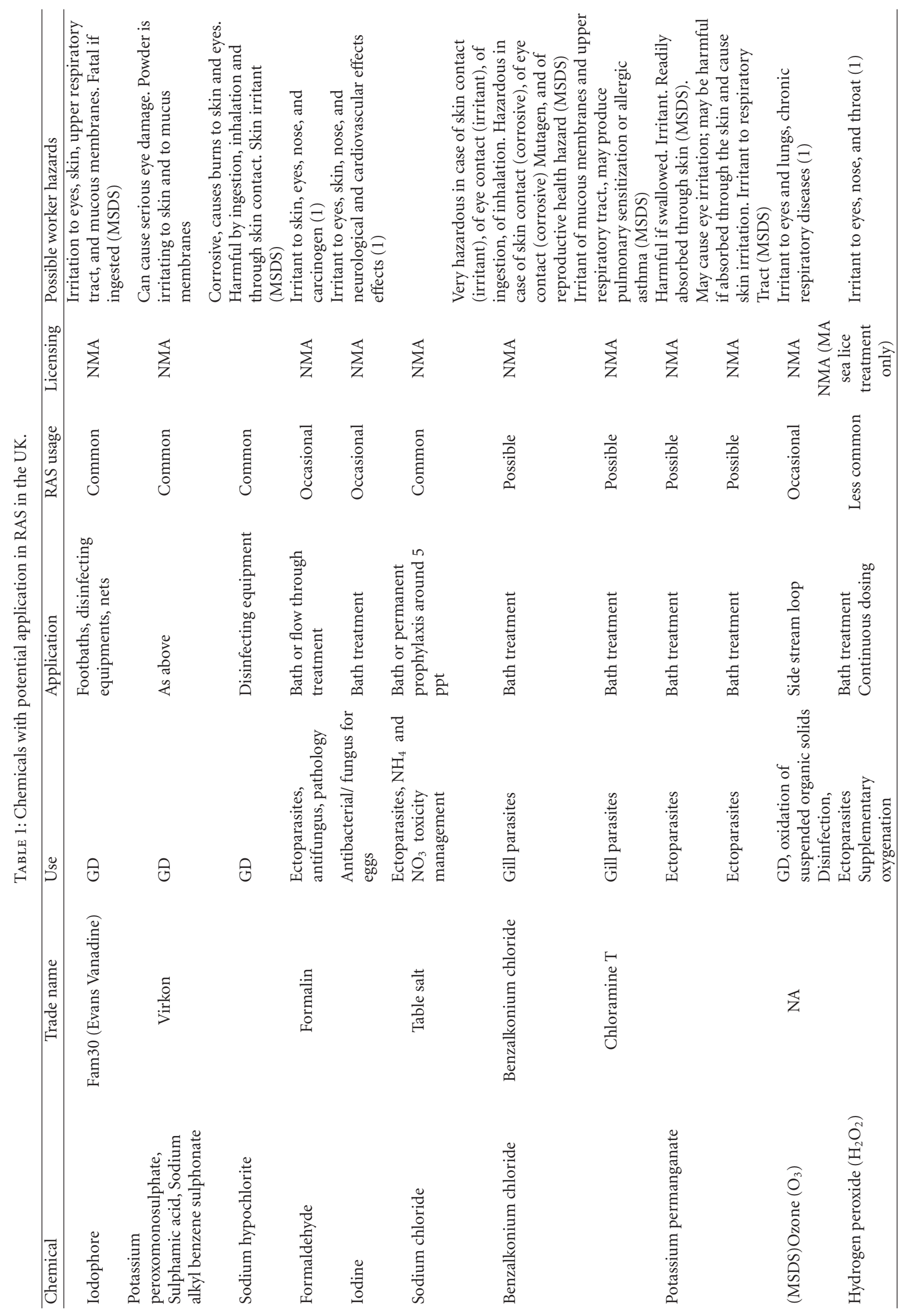




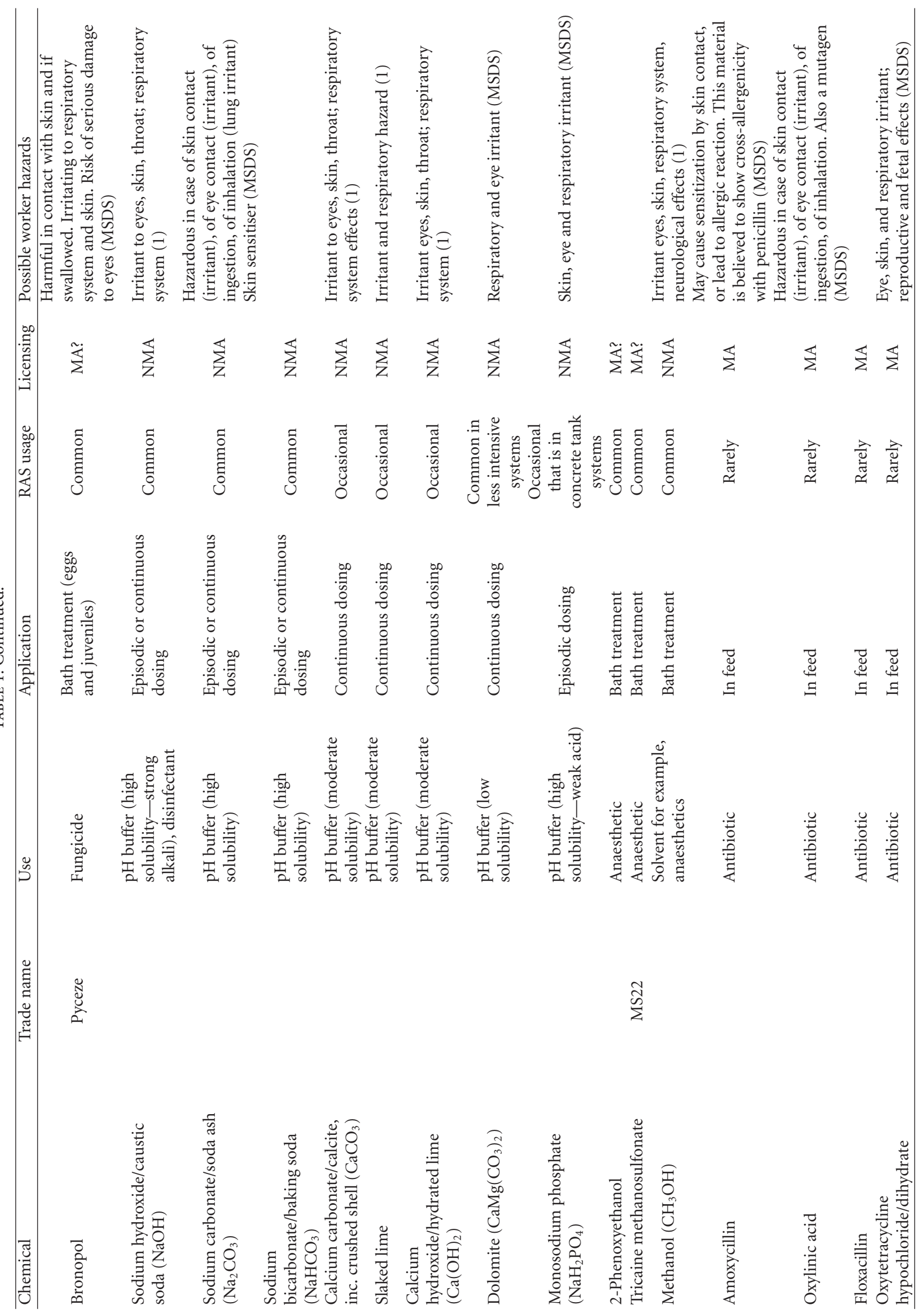




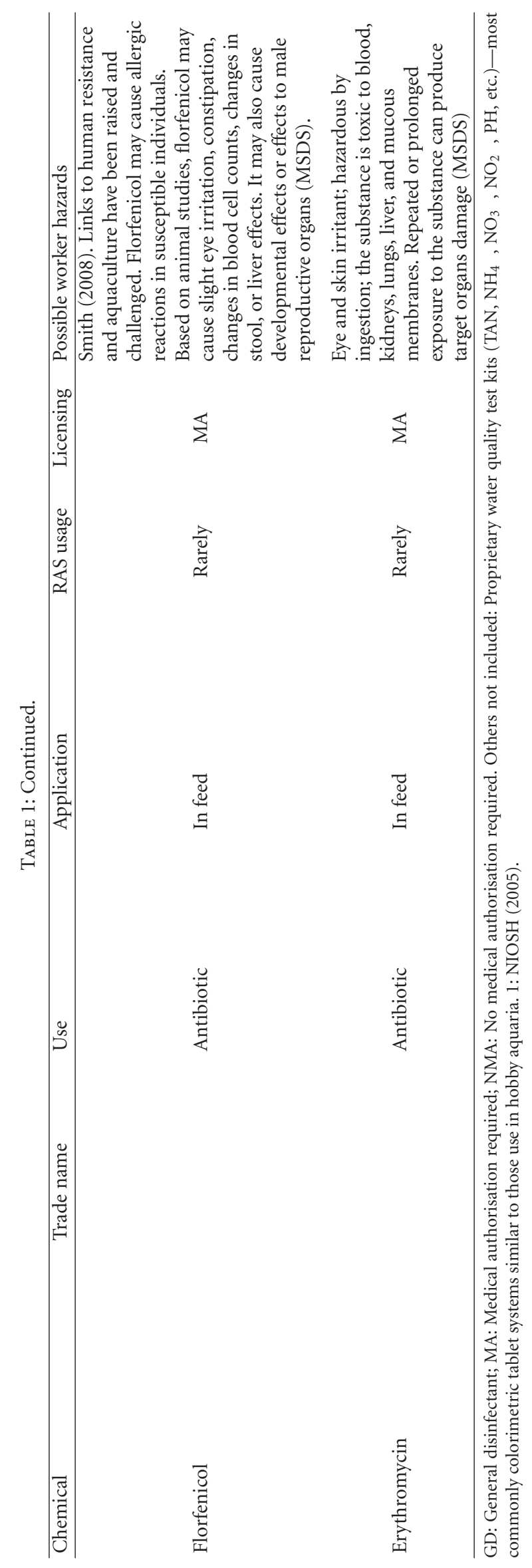


One farmer interviewed with a production target of $200 \mathrm{mt}$ could manage only $150 \mathrm{mt}$. Such pressures may be linked to investment costs of a new enterprise and sometimes to problems with support companies that helped set up and sales. Hence farmer diversification into tilapia fish farming may be viewed positively as a means to improve viability but unattainable targets could prove stressful. Another farmer engaged in tilapia production felt stressed due to the labour intensive nature of tilapia aquaculture. His system was a relatively small unit with high production costs. Factoring in such things to a HIA will depend upon knowledge of the regional and local economy and labour markets as well as an understanding of market opportunities for tilapia in different sized and differently configured farm units.

One tilapia farmer proposed using the kitchen of a local pub for filleting as this would avoid site certification expenses. The process on or off farm entails risks from cuts, skin hazards, and costs of suitable personal protective equipment which would have to be factored into the costs of the tilapia farming activity. Additionally there could be hygiene and food handing challenges and control of the premises would lie primarily with the pub owner/landlord as could staff training and supervision. Deficient fish handling and facilities might introduce pathogens to the fish fillets. If tilapia farmers used their own farm shops, this would reduce food miles but could present the same food hygiene problems and the particular and more demanding challenges of fish compared to much of the traditional product range.

\subsection{Socioeconomic Dimensions of a UK Tilapia PHIA-Com-} munity Impacts_- "Indirect" Impacts on Public Health and Well-Being. There are positive economic impacts, of variable size, to be gained from tilapia production in rural, suburban, or urban parts of the UK. These will come from a variety of sources including plant and equipment needed in the production process, input materials purchased, and other indirect effects. In addition income and employment multipliers will have direct, indirect, and induced impacts and importantly may occur in areas which are otherwise deprived of economic activity relative to other areas. Such boosts to local economies can make significant differences to society's wider well-being through improved, or enabled, provision of housing, schools, medical care, and related contributions to social infrastructure. Economic factors that play into the public health assessments of tilapia farming would include the number and size of UK tilapia enterprises, the numbers of people involved in production and distribution, and the nature of communities within which they worked as well the number and type of consumers in the UK. Approximately 12 tilapia production units exist in the UK and 3 or 4 of these are on a commercial scale with 1.5 full-time equivalent staff employed. Tilapia farms that are viable will add to "social capital" and will contribute to local service capacity impacts, education, health and social services, community viability, and cultural and social infrastructure impacts. Population retention and possible expansions have positive environmental diversity and landscape impacts.

Economic impacts also affect social factors. Over the years, efforts have been made to produce social impact assessment (SIA) statements relating to public and private sector projects. Social Impact Assessment "includes the processes of analysing, monitoring and managing the intended and unintended social consequences, both positive and negative, of planned interventions (policies, programs, plans, projects) and any social change processes invoked by those interventions. Its primary purpose is to bring about a more sustainable and equitable biophysical and human environment" [73]. The methodologies used in these are many and varied. Few have addressed fisheries explicitly and none tilapia. One fishery SIA has tried to move beyond guidelines to understanding causal factors and emergent relationships [74]. Such factors have been discussed earlier in this paper.

Assessing the health benefits of employment creation is complex. Assuming that people are able, physically and mentally, to work, good work is generally viewed as good for mental and physical health. Bad work would be viewed as bad for health but defining good and bad work is challenging. No work is usually bad for mental and physical health unless people are incapacitated or sick. Tilapia farming could have a number of socioeconomic effects in a number of settings and some of these were flagged by the farmers interviewed. For some, it was an exciting entrepreneurial activity adding to income often outside their ordinary working hours. For some, it was viewed as an important supplement to a basic income. For others_-working as employees_it either helped to guarantee existing work or could produce additional work on top of usual work, or it might lead to new part-time and full-time jobs. Stresses-financial, time, organizational, and physical — were also produced by moves into tilapia farming.

Where tilapia farming has helped to secure or increase local employment in rural and remote communities across the UK, albeit on a very small scale this will have impacted on wider community health and viability considerations. The FAO criteria of sustainable livelihoods provide a means to assess such activities even in "developed" countries [75]. "Livelihoods are sustainable when they can cope with and recover from stresses and shocks and maintain or enhance capabilities and assets (current standard of living) without undermining the natural resource base. Livelihoods consist of the capabilities and the activities required for a means of living. Human, social, physical, natural, and financial resources are involved". Such a concept has increasing relevance in rural and remote and indeed urban and periurban communities across the world.

Where UK tilapia production is sustainable, taps into existing energy resources, and opens up and fills niches in local markets, then it should contribute to resilience and sustainability. Sometimes in multiply deprived communities and in countries like Thailand, the benefits to a sustainable livelihood framework may be far greater.

3.4. Consumer and Customer Preferences Likely to Affect Impacts. The analysis of consumer perspectives on tilapia helps to inform certain aspects of the impact assessments although its primary objective was to examine how tilapia were perceived and could be marketed depending on factors such as production, quality, price, labeling, and with 
particular regard to competing substitutes. The consumer research began in 2005 and used a combination of focus groups, a product placement exercise, and interviews with people in the seafood supply chain as described in the methods section. The focus group participants had a selfdeclared interest in food and health and were fish consumers who were allocated to one of 11 groups with a total of 90 consumers. Participants reflected a wide section of society in terms of socioeconomic characteristics including age, gender, class, and education levels. Themes explored included participants' attitudes to health, food, and fish, the perceived health benefits of fish consumption, sustainable food production, organic fish and participants' awareness, perceptions, and purchase habits concerning tilapia. Discussions also included fish quality, freshness, packaging, and wider concerns with healthy eating, including avoiding or reducing obesity $[3,4]$.

In large fish markets, it appeared that most customers preferred frozen tilapia because of its low price in relation to fresh tilapia and this linked with values attached to the fish by ethnic minorities [4]. This presents suppliers and sellers with a distinct set of occupational health hazards as well as environmental impacts due to heating of freezers, other temperature controlled storage, and transportation of tilapia products.

Consumer concerns and perceptions of tilapia are central to the viability or otherwise of tilapia farming. PHIAs play into this and may help to inform UK tilapia farmers, with a solid evidence base or clear indications of areas of uncertainty, with regard to

(i) the costs, benefits, risks, and appropriate scale of tilapia production units,

(ii) the health effects of consuming tilapia,

(iii) health and safety considerations for themselves and their workforce in operating production units,

(iv) any likely environmental consequences involved in production, distribution, and disposal,

(v) likely socioeconomic and community impacts.

\section{Discussion}

PHIAs that integrate information on environmental and occupational health could be used at different levels depending on the staff and resources available for compiling them, availability of data, and variations in types of production in different localities. So, for example, it might be possible to produce some sort of national PHIA for UK tilapia production available to the fish farming industry or Central Government that would be able to assess such elements as types of production system, energy and water usage linked to more typical environmental impacts, likely pollution, employment benefits and job creation or protection, socioeconomic effects on communities, typical occupational health and safety risks, and consumer benefits from or risk with tilapia consumption. At a regional or local level, there could be customised templates for a softer touch PHIA that drew on existing data and particular types and scale of tilapia production. Hence when an economic development body or farm wished to consider this fish farming option and a local or community body wished to draw on a PHIA to assess tilapia benefits and drawbacks, they would have access to a worked up PHIA model and related data that might meet all their needs and would not demand any work on their part. Updating such PHIAs at a national level would be necessary to take into account any changes in inputs, outputs, technologies, and substances.

Checklists, at appropriate levels, would help to ensure that key elements of a HIA have been constructed and addressed at the beginning. Industry standards designed for certification of tilapia farming may provide comprehensive checklists that could be built into and help to frame HIAs for use at various especially local levels. For example, the US Aquaculture Certification Council Scheme Tilapia farm checks cover community matters linked to water usage, worker health and safety, drugs and chemical management, microbial sanitation, wetland conservation and biodiversity protection, effluent management, fishmeal and fish oil conservation, harvest and transport, soil and water conservation, control of escapes and use of GMOs, storage and disposal of supplies, and animal welfare [76]. In some respects the WWF standard for tilapia aquaculture, like the US standard, provides a checklist for a good PHIA and highlights the topics that need to be assessed [19]. In addition to meeting legal standards, criteria to include would be habitat and local biodiversity, water conservation, species diversity including impacts of escapes and risks from transgenic fish, responsible resource usage, environmentally sound fish health and welfare, and social responsibility including employee working conditions, collective bargaining rights, and community concerns and interactions.

In methodological terms, the hazard and risk perception, assessment, and potential management processes are problematic as are cost and risk benefit assessments where data are limited or incomplete. The hazard assessment generally proves easier than other steps and can often but not always be less subjective than the risk assessments. A large number of confounders exist in terms of trying to tease out impacts. For example, there can be multiple contributions to wellbeing linked to creation of tilapia farming employment or consumption of tilapia in diets with greater or lesser variety. There may be a high level of self-selection in terms of the tilapia farms visited and the information made available in a published form on tilapia farming standards. Small-scale usage versus large-scale production will create very different impacts as will urban/suburban/rural/remote tilapia production linked potentially to very different socioeconomic and environmental profiles. No extensive tilapia production exists across the UK though HIAs can be prospective, concurrent, or retrospective.

HIAs are often based on both national and international regulations and controls and an assumption that such controls will cover all likely health impacts and will be enforced. They may also draw on codes of practice and industry guidance about good practice. At times of deregulation and reduced staffing levels in inspection agencies, it would be unwise to assume that all production standards for tilapia are observed and that the likely impacts identified in this paper 


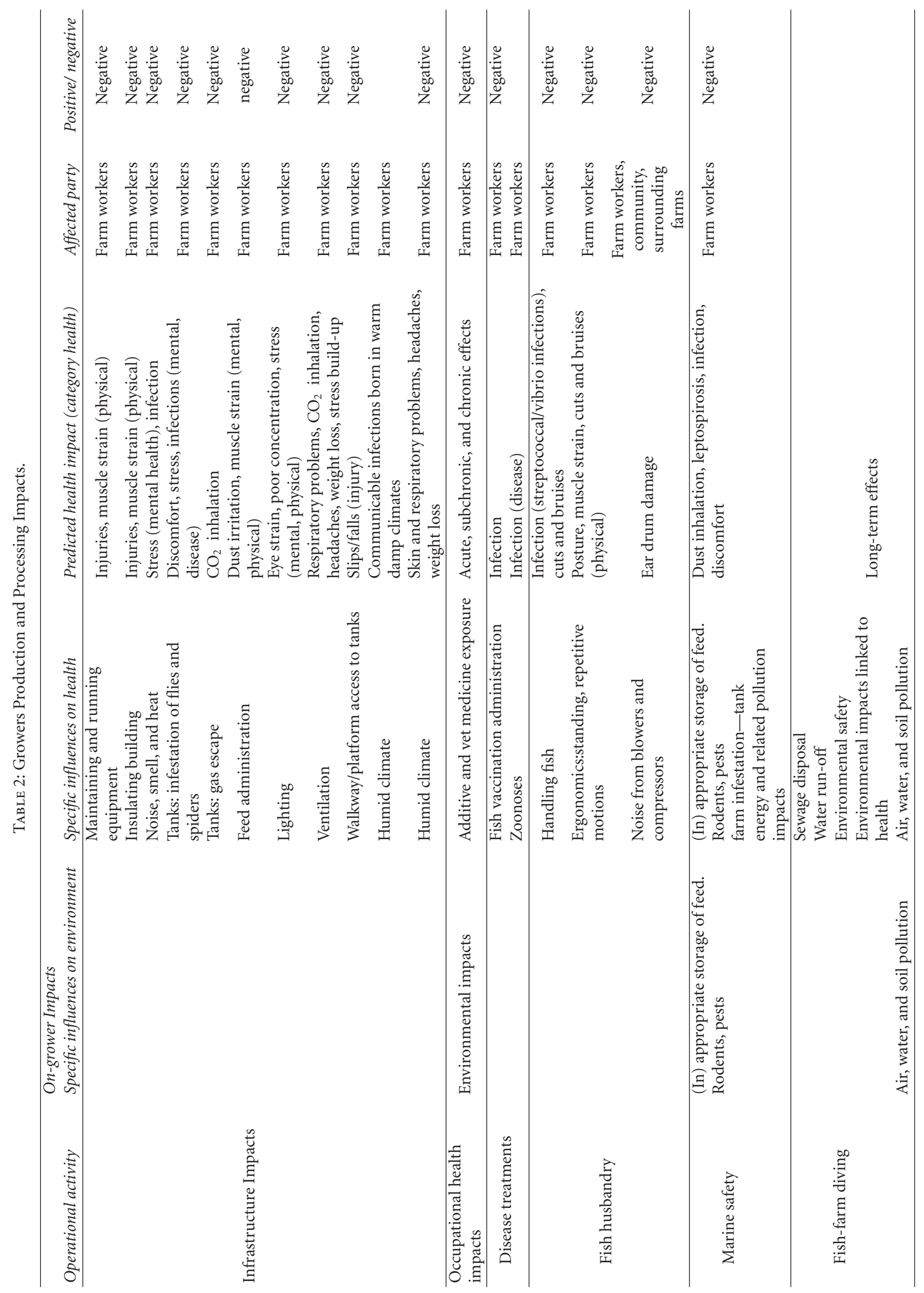


TABLE 3: Health impacts.

\begin{tabular}{|c|c|c|c|c|}
\hline Operational activity & Specific influences on health & Predicted health impact & Affected party & Positive/negative \\
\hline \multirow{3}{*}{ Nutritional impact } & Omega 3 & Reduced CHD & Consumer & Positive \\
\hline & $n-3$ fatty acids & & Consumer & Positive \\
\hline & Cholesterol & Reduced cholesterol & Consumer & Positive \\
\hline \multirow{3}{*}{ Natural impacts } & Contamination & High toxicity & Consumer & Negative \\
\hline & & High toxicity & Consumer & Negative \\
\hline & Parasites & Fish food poisoning & Consumer & Negative \\
\hline \multirow{3}{*}{$\begin{array}{l}\text { Food handling } \\
\text { impacts }\end{array}$} & Preparation & Poisoning & Consumer & Negative \\
\hline & Preparation: & $\begin{array}{l}\text { Streptococcus: high temp and blood } \\
\text { pressure, Lymphangitis, Cellulitis }\end{array}$ & Cook/chef & Negative \\
\hline & Freshness/quality & Seafood poisoning & Consumer & Negative \\
\hline $\begin{array}{l}\text { Farmed, rather than } \\
\text { wild seafood source }\end{array}$ & Mercury intake & $\begin{array}{l}\text { Reduced mercury levels as not absorbed } \\
\text { from see }\end{array}$ & Consumer & Positive \\
\hline
\end{tabular}

TABle 4: Distribution Impacts.

\begin{tabular}{|c|c|c|c|}
\hline Operational activity & Specific influences on health & Predicted health impact & Affected party \\
\hline Slaughter & & $\begin{array}{l}\text { Infection (streptococcal/Vibrio } \\
\text { infections), cuts, and bruises }\end{array}$ & Farmworkers/fishmonger/chef/consumer \\
\hline $\begin{array}{l}\text { Slaughter } \\
\text { method-machine }\end{array}$ & $\begin{array}{l}\text { Fish wastage, fuel/energy } \\
\text { consump }\end{array}$ & & Farmworkers/fishmonger \\
\hline $\begin{array}{l}\text { Slaughter } \\
\text { method-manual }\end{array}$ & & Repetitive strain, cuts. & Farmworkers/fishmonger/chef/consumer \\
\hline $\begin{array}{l}\text { Heading and } \\
\text { gutting-machine }\end{array}$ & $\begin{array}{l}\text { Fish wastage, fuel/energy } \\
\text { consump }\end{array}$ & & \\
\hline $\begin{array}{l}\text { Heading and } \\
\text { gutting-manual }\end{array}$ & & Repetitive strain & \\
\hline Boxing & Ice cube machine environ effects & & \\
\hline \multicolumn{4}{|l|}{$\begin{array}{l}\text { Moving to } \\
\text { wholesale/retailer }\end{array}$} \\
\hline \multicolumn{4}{|l|}{ Storage } \\
\hline Fish miles & Mode of transportation & & \\
\hline Fish miles & Number of journeys & & \\
\hline \multicolumn{4}{|l|}{$\begin{array}{l}\text { Time impact farmgate to } \\
\text { retail }\end{array}$} \\
\hline \multicolumn{4}{|l|}{ Presentation/quality } \\
\hline $\begin{array}{l}\text { Product form } \\
\text { (fillet/whole) }\end{array}$ & & & \\
\hline
\end{tabular}

always emerge: as our section on tilapia farming practice sometimes demonstrates.

Exploring the impacts of tilapia production is possible but somewhat restricted at the moment by lack of comprehensive and good quality data on certain topics. Nevertheless, there are pockets of emerging data sufficiency and there are also some good tools available to draft a PHIA that could benefit producers, retailers, public bodies, and communities where tilapia production may occur. However, questions remain about how transferable data will be between countries and between types of tilapia production. This remains a major research gap that needs to be filled in the future.

\section{Conclusion}

It is feasible to scope out what fields should be in a tilapia PHIA but not yet possible to fill in all those fields with valid and verifiable data. Based on the data and analysis presented previously, it is possible to provide a framework if not for a comprehensive PHIA, then for a working tool (Tables 2, 3 , and 4). This could benefit a range of groups seeking 
to establish a better and fuller picture of what health and environmental impacts tilapia farming may or will have.

\section{Abbreviations}

$\begin{array}{ll}\text { AST: } & \text { Activated suspension technology } \\ \text { CIDA: } & \text { Canadian international development agency } \\ \text { DHA: } & \text { Docosahexaenoic acid } \\ \text { EIA: } & \text { Environmental impact assessment } \\ \text { EHIAs: } & \text { Environmental health impact assessments } \\ \text { FA: } & \text { Favourable fatty acid } \\ \text { FAO: } & \text { Food and Agriculture Organization of the } \\ & \text { United } \\ \text { GMOs: } & \text { Genetically engineered organisms } \\ \text { HACCP: } & \text { Hazard analysis at critical control point } \\ \text { HIA/HIAs: } & \text { Health impact assessment(s) } \\ \text { IEE: } & \text { Independent external evaluation } \\ \text { LCAs: } & \text { Life cycle analyses } \\ \text { OHIAs: } & \text { Occupational health impact assessments } \\ \text { OIE: } & \text { World Organization for Animal Health } \\ \text { PHIA/PHIAs: } & \text { Public health impact assessment(s) } \\ \text { RAS: } & \text { Recirculation aquaculture systems } \\ \text { RELU: } & \text { Rural economy and land use } \\ \text { SIA: } & \text { Social impact assessment } \\ \text { WHO: } & \text { World Health Organization } \\ \text { WRULD: } & \text { Work-related upper limb disorder } \\ \text { WWF: } & \text { Word Wildlife Federation. }\end{array}$

\section{Conflict of Interests}

The authors declared that they have no conflict of interests with regard to this paper.

\section{Authors' Contributions}

All authors made a substantial contribution to the design, acquisition of data, or analysis and interpretation of data in the paper. A. Watterson, D. Little, and J. A. Young were involved in the conception of the study. A. Watterson, J. A. Young, D. Little, and F. Murray were involved in drafting the manuscript. K. A. Boyd and L. Doi were involved in revising it. All authors have given final approval of the version to be published.

\section{Acknowledgment}

The authors would like to acknowledge the RCUK Rural Economy and Land Use programme for funding the project on which this paper is based.

\section{References}

[1] D. C. Little, F. Murray, E. Azim et al., "Options for producing a warm-water fish in the UK: limits to "Green Growth"?" Trends in Food Science and Technology, vol. 19, no. 5, pp. 255-264, 2008.

[2] A. Watterson, D. C. Little, J. A. Young, K. Boyd, E. Azim, and F. Murray, "Towards integration of environmental and health impact assessments for wild capture fishing and farmed fish with particular reference to public health and occupational health dimensions," International Journal of Environmental Research and Public Health, vol. 5, no. 4, pp. 258-277, 2008.

[3] J. A. Young, D. C. Little, A. Watterson et al., "Growing green: the emergent role of non-tilapia attributes in marketing tilapia," Aquaculture Economics and Management, vol. 14, no. 1, pp. 63-79, 2010.

[4] Rural Economy and Land Use Programme (RELU) Project, "Warm water fish production as a diversification strategy for arable farmers," RELU Data Support Services, 2008, http://relu .data-archive.ac.uk/reluproject.asp?awardNumber=RES-22425-0066.

[5] T. Håstein, B. Hjeltnes, A. Lillehaug, J. Utne Skåre, M. Berntssen, and A. K. Lundebye, "Food safety hazards that occur during the production stage: challenges for fish farming and the fishing industry," OIE Revue Scientifique et Technique, vol. 25, no. 2, pp. 607-625, 2006.

[6] D. W. Cole, R. Cole, S. J. Gaydos et al., "Aquaculture: environmental, toxicological, and health issues," International Journal of Hygiene and Environmental Health, vol. 212, no. 4, pp. 369-377, 2009.

[7] S. J. Hall, A. Delaporte, M. J. Phillips, M. Beveridge, and M. O'Keefe, Blue Frontiers: Managing the Environmental Costs of Aquaculture, The WorldFish Center, Penang, Malaysia, 2011.

[8] WWF, "Aquaculture:tilapia," 2011, http://www.worldwildlife .org/what/globalmarkets/aquaculture/dialogues-tilapia.html.

[9] A. Sapkota, A. R. Sapkota, M. Kucharski et al., "Aquaculture practices and potential human health risks: current knowledge and future priorities," Environment International, vol. 34, no. 8, pp. 1215-1226, 2008.

[10] N. L. Judd, C. H. Drew, C. Acharya et al., "Framing scientific analyses for risk management of environmental hazards by communities: case studies with seafood safety issues," Environmental Health Perspectives, vol. 113, no. 11, pp. 1502-1508, 2005.

[11] North American HIA Practice Standards Working Group, "Minimum Elements and Practice Standards for Health Impact Assessment," Version 2, 2010, http://www.sfphes.org/ HIA_Tools/HIA_Practice_Standards.pdf.

[12] Canadian International Development Agency (CIDA), "Environmental handbook for community development initiative," 2ed, 2011, http://www.acdi-cida.gc.ca/acdi-cida/acdi-cida.nsf/ eng/EMA-218123621-NNZ.

[13] P. Henriksson, "Life Cycle Assessment (LCA) of aquatic products," 2011, http://www.beijer.kva.se/ftp/WIOAQUA/Henriksson.pdf.

[14] N. Pelletier and P. Tyedmers, "Life cycle considerations for improving sustainability assessments in seafood awareness campaigns," Environmental Management, vol. 42, no. 5, pp. 918-931, 2008.

[15] A. Watterson, D. Little, J. A. Young et al., An International Review of Health and Sustainability in the Food and Drinks Industry, Scottish Government, Edinburgh, UK, 2011.

[16] N. Pelletier and P. Tyedmers, "Life cycle assessment of frozen tilapia fillets from indonesian lake-based and pond-based intensive aquaculture systems," Journal of Industrial Ecology, vol. 14, no. 3, pp. 467-481, 2010.

[17] J. Aubin, R. T. Mungkung, T. Prihadi et al., "Application of Life Cycle Assessment for sustainable aquaculture management: a case study of two-net cage aquaculture systems of carp and tilapia in Cirata reservoir," Indonesia, http://www.rennes.inra .fr/umrsas/content/download/3395/39898/version/1/file/WAS + conference_LCA+of+cage+aquaculture+in+Indonesia.doc. 
[18] M. Corson and J. Aubin, LCA of Animal Production: from Temperate to Tropical Systems. Case Studies, INRA, Rennes, France, 2010.

[19] WWF, International Standards for Responsible Tilapia Aquaculture, Tilapia Aquaculture Dialogue, 2009.

[20] B. Belton, F. Murray, J. A. Young, T. Telfer, and D. C. Little, "Passing the panda standard: a TAD off the mark?" Ambio, vol. 39, no. 1, pp. 2-13, 2010.

[21] M. Allsop, P. Johnston, and D. Santillo, Challenging the Aquaculture Industry on Sustainability, Greenpeace Labs, Plymouth, UK, 2008.

[22] E. J. Brunner, P. J. S. Jones, S. Friel, and M. Bartley, "Fish, human health and marine ecosystem health: policies in collision," International Journal of Epidemiology, vol. 38, no. 1, pp. 93-100, 2009.

[23] O. Torrisson, R. E. Olsen, R. Toresen et al., "Atlantic salmon (Salmo salar): the "Super-Chicken" of the sea?" Reviews in Fisheries Science, vol. 19, no. 3, pp. 257-278, 2011.

[24] T. van Phan, A. K. Ersbøll, K. V. Nguyen, H. Madsen, and A. Dalsgaard, "Farm-level risk factors for fish-borne zoonotic trematode infection in integrated small-scale fish farms in northern Vietnam," PLoS Neglected Tropical Diseases, vol. 4, no. 7, article e742, 2010.

[25] FAO, "The introduction and distribution of tilapias in Asia and the Pacific. Tilapias as alien aquatics in Asia and the Pacific: a review," 2007, http://www.fao.org/docrep/007/ y5728e/y5728e04.htm.

[26] HSE, "A guide to measuring health and safety performance," 2001, http://www.hse.gov.uk/opsunit/perfmeas.pdf.

[27] D. T. R. Moreau and B. Neis, "Occupational health and safety hazards in Atlantic Canadian aquaculture: laying the groundwork for prevention," Marine Policy, vol. 33, no. 2, pp. 401-411, 2009.

[28] M. L. Myers, "Review of occupational hazards associated with aquaculture," Journal of Agromedicine, vol. 15, no. 4, pp. 412426, 2010.

[29] R. K. Morgan, "Health and impact assessment: are we seeing closer integration?" Environmental Impact Assessment Review, vol. 31, no. 4, pp. 404-411, 2011.

[30] UK Network Health for All, "Health Impact Assessments," Briefing paper 9, UK Network Health for All, London, UK, 2001.

[31] H. Tacio, "Is Eating Tilapia Nutritious or Harmful to Health?" Gaia Discovery, 2009, http://www.gaiadiscovery.com/marinelife-latest/is-eating-tilapia-nutritious-or-harmful-to-health .html.

[32] K. L. Weaver, P. Ivester, J. A. Chilton, M. D. Wilson, P. Pandey, and F. H. Chilton, "The content of favorable and unfavorable polyunsaturated fatty acids found in commonly eaten fish," Journal of the American Dietetic Association, vol. 108, no. 7, pp. 1178-1185, 2008.

[33] I. T. Karapanagiotidis, M. V. Bell, D. C. Little, A. Yakupitiyage, and S. K. Rakshit, "Polyunsaturated fatty acid content of wild and farmed tilapias in Thailand: effect of aquaculture practices and implications for human nutrition," Journal of Agricultural and Food Chemistry, vol. 54, no. 12, pp. 4304-4310, 2006.

[34] K. Young, "Omega-6 (n-6) and omega-3 (n-3) fatty acids in tilapia and human health: a review," International Journal of Food Sciences and Nutrition, vol. 60, supplement 5, pp. 203$211,2009$.

[35] D. H. Lee and D. R. Jacobs, "Inconsistent epidemiological findings on fish consumption may be indirect evidence of harmful contaminants in fish," Journal of Epidemiology and Community Health, vol. 64, no. 3, pp. 190-192, 2010.
[36] S. P. J. van Leeuwen, M. J. M. van Velzen, C. P. Swart, I. van der Veen, W. A. Traag, and J. de Boer, "Halogenated contaminants in farmed salmon, trout, tilapia, pangasius, and shrimp," Environmental Science and Technology, vol. 43, no. 11, pp. 4009-4015, 2009.

[37] L. C. Del Gobbo, J. A. Archbold, L. D. Vanderlinden, C. S. Eckley, M. L. Diamond, and M. Robson, "Risks and benefits of fish consumption for childbearing women," Canadian Journal of Dietetic Practice and Research, vol. 71, no. 1, pp. 41-45, 2010.

[38] FDA, "Mercury levels in commercial fish and shellfish (19902010)," 2011, http://www.fda.gov/Food/FoodSafety/ProductSpecificInformation/Seafood/FoodbornePathogensContaminants/Methylmercury/ucm115644.htm.

[39] A. Watterson, "Agricultural, forestry and fisheries' health and safety," in Munkman's Employers Liability, B. Cotter and D. Bennett, Eds., pp. 788-799, Elsevier, London, UK, 2009.

[40] B. Z. Zhang, H. Y. Yu, J. You, and E. Y. Zeng, "Input pathways of organochlorine pesticides to typical freshwater cultured fish ponds of south China: hints for pollution control," Environmental Toxicology and Chemistry, vol. 30, no. 6, pp. 1272-1277, 2011.

[41] N. Suanyuk, F. Kong, D. Ko, G. L. Gilbert, and K. Supamattaya, "Occurrence of rare genotypes of Streptococcus agalactiae in cultured red tilapia Oreochromis sp. and Nile tilapia O. niloticus in Thailand-relationship to human isolates?" Aquaculture, vol. 284, no. 1-4, pp. 35-40, 2008.

[42] A. G. J. Tacon and M. Metian, "Aquaculture feed and food safety: the role of the food and agriculture organization and the codex alimentarius," Annals of the New York Academy of Sciences, vol. 1140, pp. 50-59, 2008.

[43] N. E. Adler, J. Koschorreck, and B. Rechenberg, "Environmental impact assessment and control of pharmaceuticals: the role of environmental agencies," Water Science and Technology, vol. 57, no. 1, pp. 91-97, 2008.

[44] A. B. A. Boxall, L. A. Fogg, P. A. Blackwell, P. Kay, E. J. Pemberton, and A. Croxford, "Veterinary medicines in the environment," Reviews of Environmental Contamination and Toxicology, vol. 180, pp. 1-91, 2004.

[45] UK Marine Special Areas of Conservation, "Chemicals used in Fish Farms," 2011, http://www.ukmarinesac.org.uk/activities/water-quality/wq8_22.htm.

[46] C. Siffel and A. E. Czeizel, "Using the Hungarian Birth Defects Registry for surveillance, research and intervention," Central European Journal of Public Health, vol. 5, no. 2, pp. 79-81, 1997.

[47] G. L. Jensen and K. J. Greenlees, "Public health issues in aquaculture," Revue Scientifique et Technique, vol. 16, no. 2, pp. 641-651, 1997.

[48] E. M. Thurman, J. E. Dietz, and E. A. Scribner, Occurrence of Antibiotics in Water from Fish Hatcheries, vol. 120, no. 2, U.S. Geological Survey, 2003.

[49] WHO, Expert Workshop on Non-Human Antimicrobial Usage and Antimicrobial Resistance: Scientific Assessment, WHO, Geneva, Switzerland, 2003.

[50] WHO, Report of a Joint FAO/OIE/WHO Expert Consultation on Antimicrobial Use in Aquaculture and Antimicrobial Resistance-Seoul, Republic of Kore, WHO, Geneva, Switzerland, 2006

[51] A. R. Sapkota, L. Y. Lefferts, S. McKenzie, and P. Walker, "What do we feed to food-production animals? A review of animal feed ingredients and their potential impacts on human health," Environmental Health Perspectives, vol. 115, no. 5, pp. 663-670, 2007. 
[52] K. Grave, M. K. Hansen, H. Kruse, M. Bangen, and A. B. Kristoffersen, "Prescription of antimicrobial drugs in Norwegian aquaculture with an emphasis on "new" fish species," Preventive Veterinary Medicine, vol. 83, no. 2, pp. 156-169, 2008.

[53] "Consensus Building Institute/WWF USA: Tilapia aquaculture dialogue. Draft Meeting Summary," WWF Washington, 2008.

[54] D. J. Macintosh, "Risks associated with using methyl testosterone in tilapia farming," http://media.sustainablefish.org/ MT_WP.pdf.

[55] A. A. Gajadhar, W. B. Scandrett, and L. B. Forbes, "Overview of food-and water-borne zoonotic parasites at the farm level," OIE Revue Scientifique et Technique, vol. 25, no. 2, pp. 595-606, 2006.

[56] Y. Torgersen and T. Håstein, "Disinfection in aquaculture," OIE Revue Scientifique et Technique, vol. 14, no. 2, pp. 419434, 1995.

[57] K. Kümmerer, "Resistance in the environment," Journal of Antimicrobial Chemotherapy, vol. 54, no. 2, pp. 311-320, 2004.

[58] F. Angulo, "Antimicrobial agents in aquaculture: potential impact on public health," Alliance for the Prudent Use of Antibiotics, vol. 18, pp. 1-4, 2008.

[59] P. Smith, "Aquaculture and florfenicol resistance in Salmonella enterica typhimurium DT104," Emerging Infectious Diseases, vol. 14, no. 8, pp. 1327-1328, 2008.

[60] F. C. Cabello, "Heavy use of prophylactic antibiotics in aquaculture: a growing problem for human and animal health and for the environment," Environmental Microbiology, vol. 8, no. 7, pp. 1137-1144, 2006.

[61] P. H. Serrano, "Responsible Use of Antibiotics in aquaculture," Tech. Rep. 469, FAO, Rome, Italy, 2005.

[62] I. A. Bakar, M. K. Ayub, A. M. Yatim, and N. A. Sani, "Pesticide and antibiotic residues in freshwater aquaculture fish: chemical risk assessment from farm to table," Asian Journal of Food and Agro-Industry, vol. 3, no. 3, pp. 328-334, 2010.

[63] FAO, Technical Consultation on the Guidelines on Aquaculture Certification. Revised Draft Technical Guidelines on Aquaculture Certification, FAO, Rome, Italy, 2010.

[64] M. R. Weinstein, M. Litt, D. A. Kertesz et al., "Invasive infections due to a fish pathogen, Streptococcus iniae," New England Journal of Medicine, vol. 337, no. 9, pp. 589-594, 1997.

[65] J. A. Plumb, "Infectious diseases of tilapia," in Tilapia Aquaculture in the Americas, B. A. Costa-Pierce and J. E. Rakocy, Eds., vol. 1, pp. 212-218, World Aquaculture Society, Baton Rouge, La, USA, 1997.

[66] N. Bisharat and R. Raz, "Vibrio infection in Israel due to changes in fish marketing," The Lancet, vol. 348, no. 9041, pp. 1585-1586, 1996.

[67] G. J. Flick, Bacterial, Chemical Residues Impact Tilapia Quality, Global Aquaculture Advocate, 2008.

[68] FAO, "Public Health and Livestock-Fish," Geneva, Switzerland, FAO document repository, 2006, http://www.fao.org/ docrep/006/y5098e/y5098e07.htm.

[69] D. Priyan and H. Smith, "Environmental impact assessment as a management tool for the use of chemicals for fish farming in the UK," Aquaculture International, vol. 2, no. 1, pp. 59-64, 1994.

[70] ECB, "Risk Assessment Report for Sodium Hypochlorite," European Chemicals Bureau (ECB), 2006, http://esis.jrc.ec .europa.eu/doc/existing-chemicals/risk_assessment/REPORT/ sodiumhypochloritereport045.pdf.
[71] NIOSH, NIOSH Pocket Guide to Chemical Hazards, CDC, Cincinnati, Ohio, USA, 2005.

[72] N. Noisel, M. Bouchard, and G. Carrier, "Evaluation of the health impact of lowering the formaldehyde occupational exposure limit for Quebec workers," Regulatory Toxicology and Pharmacology, vol. 48, no. 2, pp. 118-127, 2007.

[73] F. Vanclay, "International principles for social impact assessment," Impact Assessment and Project Appraisal, vol. 21, no. 1, pp. 5-11, 2003.

[74] F. Lord, "Understanding social impacts by using new variables and a causal model diagram in New England fisheries," Impact Assessment and Project Appraisal, vol. 29, no. 1, pp. 59-68, 2011.

[75] FAO, Socio-Economic \& Livelihood Analysis in Investment Planning, FAO, 2008.

[76] Aquaculture Certification Council, "Best Aquaculture Practice Schemes USDA,” The Tilapia Standard, 2011, http://www.aquaculturecertification.org/index.php?option $=$ com_content $\&$ task=view\&id $=105 \&$ Itemid $=47$. 


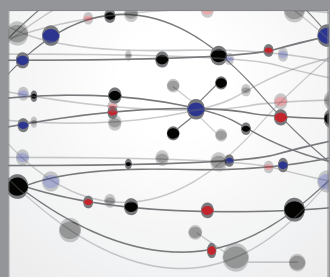

The Scientific World Journal
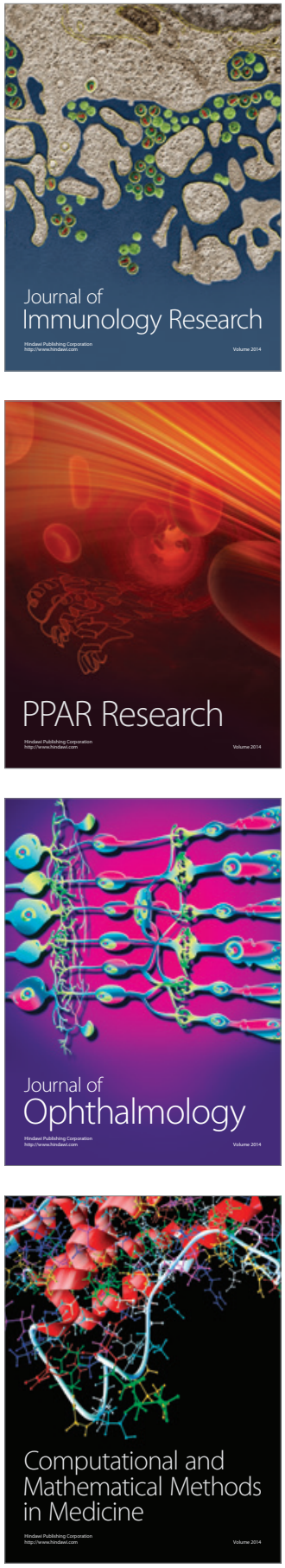

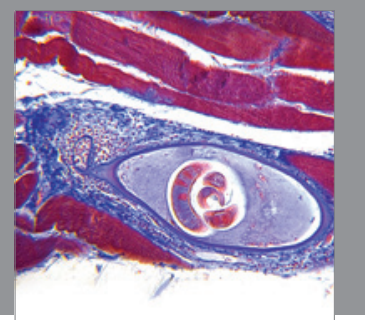

Gastroenterology

Research and Practice
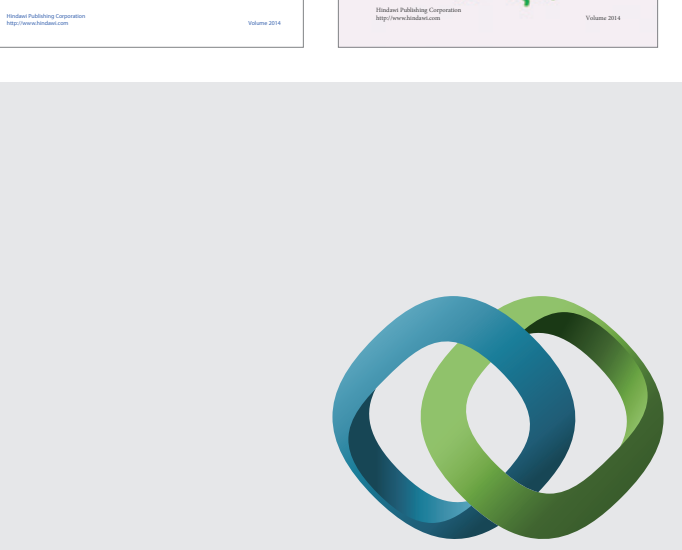

\section{Hindawi}

Submit your manuscripts at

http://www.hindawi.com
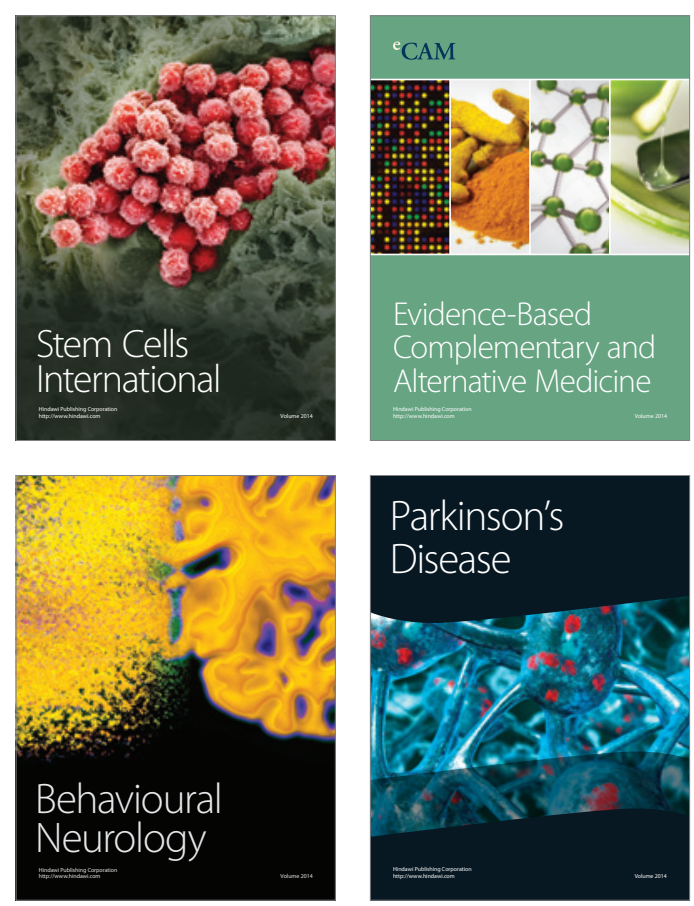

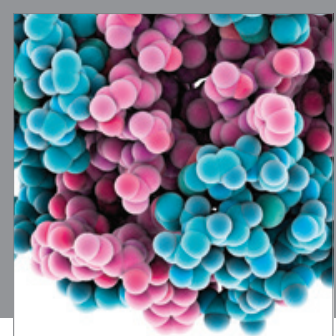

Journal of
Diabetes Research

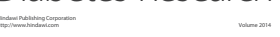

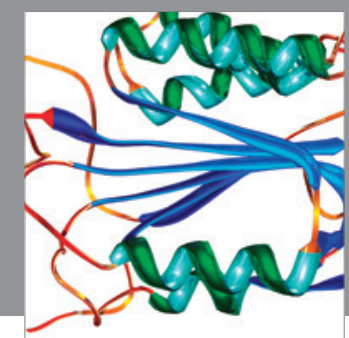

Disease Markers
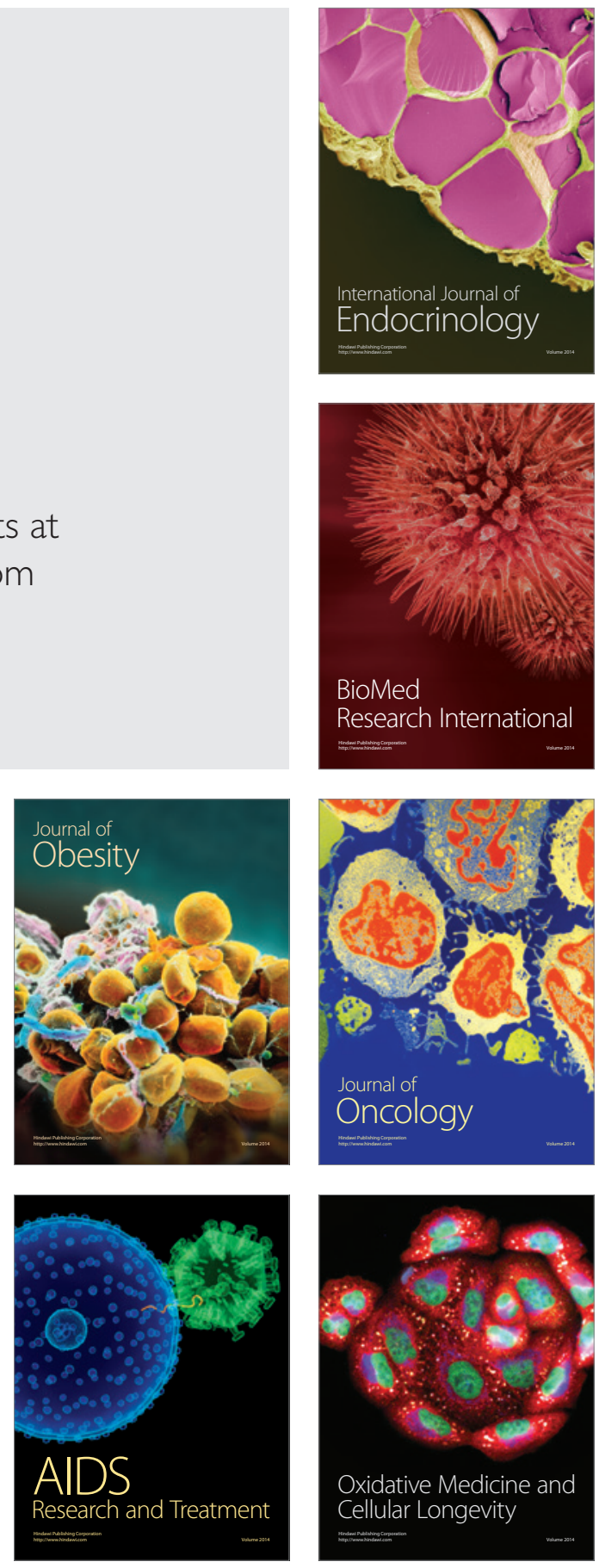